\title{
Faktor-Faktor Kunci Kesuksesan Implementasi Manajemen Pengetahuan pada PT Unilever Indonesia Tbk.
}

\author{
Windarti \\ Alumni Departemen Manajemen, Fakultas Ekonomi dan Manajemen \\ Institut Pertanian Bogor \\ Anggraini Sukmawati \\ Departemen Manajemen, Fakultas Ekonomi dan Manajemen \\ Institut Pertanian Bogor \\ e-mail: anggrainism@ipb.ac.id
}

\begin{abstract}
Social environment provides organization capability in knowledge creation, transfer and implementation which leading the company into successful knowledge management by providing competitive human capital. PT. Unilever Indonesia, Tbk as successful Indonesian company in Knowledge Management was awarded the Most Admired Knowledge Enterprise (MAKE) in Asia from 2005 until 2009. The study objectives are 1) to identify knowledge management implementation 2) to analyze the gap between perceived and actual implementation factors in knowledge management 3) to analyze social environment success factor in knowledge management implementation. The primary data collection methods were using questionnaires from 86 respondents and in depth interview with Learning Specialist of PT. Unilever Indonesia, Tbk, and secondary data were collected from journals, books, company annual year reports and other related literatures. There were five knowledge management implementation approaches used by the company: human resources development, learning environment as a culture, stakeholders' knowledge as one of resources, community education and supported infrastructure and facilities. Statistical analysis showed there is no gap between perceived and actual implementation factors in knowledge management. And trust, autonomy, involvement and empowerment were the social environment key success factors in knowledge management implementation.

Keyword: Knowledge Management, PT Unilever Indonesia Tbk., Key Success Factors, Social Environment.
\end{abstract}

\section{Pendahuluan}

Perusahaan yang mampu bertahan dalam menghadapi persaingan bisnis bahkan mampu mencapai kesuksesan adalah perusahaan yang mampu menerapkan manajemen pengetahuan dengan baik (Sangkala, 2007). Salah satu komponen kritis yang dijadikan sebagai kategori kesuksesan implementasi manajemen pengetahuan adalah budaya tempat kerja yang benar sehingga karyawan termotivasi untuk memanfaatkan pengetahuan (Setiarso et al., 2009). Oleh karena itu, faktor-faktor 
lingkungan sosial pembentuk budaya tempat kerja yang dapat mendorong kesuksesan implementasi manajemen pengetahuan dipandang penting untuk diteliti.

Sejak tahun 2005 sampai 2009, PT Unilever Indonesia Tbk. telah empat kali memenangkan penghargaan Indonesian Most Admired Knowledge Enterprise (MAKE), bahkan menjadi wakil Indonesia yang mampu menjadi pemenang di tingkat Asia. Penghargaan Most Admired Knowledge Enterprise (MAKE) merupakan pengakuan atas prestasi terhadap kesuksesan perusahaan dalam menjadi knowledge based enterprise terkemuka di dunia. Prestasi ini membuktikan komitmen PT Unilever Indonesia Tbk. untuk terus membangun dan mengembangkan intellectual capital perusahaan.

Kesuksesan PT Unilever Indonesia Tbk. dalam menerapkan manajemen pengetahuan di perusahaannya tidak terlepas dari peranan lingkungan sosial. Oleh karena itu, peneliti ingin mengidentifikasi mengenai faktor-faktor kunci lingkungan sosial yang mempengaruhi kesuksesan implementasi manajemen pengetahuan di perusahaan tersebut.

Berdasarkan latar belakang yang dikemukakan sebelumnya, maka permasalahan pada penelitian dapat dirumuskan sebagai berikut:

1. Bagaimana penerapan manajemen pengetahuan pada PT Unilever Indonesia Tbk?

2. Bagaimana kesenjangan antara tingkat kepentingan faktor lingkungan sosial yang diharapkan dan yang aktual diterapkan dalam menciptakan kesuksesan implementasi manajemen pengetahuan pada PT Unilever Indonesia Tbk?

3. Bagaimana faktor lingkungan sosial mempengaruhi kesuksesan implementasi manajemen pengetahuan pada PT Unilever Indonesia Tbk?

Sejalan dengan permasalahan yang dirumuskan, maka tujuan dari penelitian ini adalah:

1. Mengidentifikasi penerapan manajemen pengetahuan pada PT Unilever Indonesia Tbk.

2. Menganalisis perbedaan antara tingkat kepentingan yang diharapkan dan tingkat kepentingan aktual penerapan kesuksesan implementasi manajemen pengetahuan pada PT Unilever Indonesia Tbk.

3. Menganalisis faktor lingkungan sosial yang mempengaruhi kesuksesan implementasi manajemen pengetahuan pada PT Unilever Indonesia Tbk.

Manfaat yang diharapkan dalam penelitan ini adalah:

1. Memberikan gambaran mengenai atribut dan faktor di lingkungan sosial yang mempengaruhi kesuksesan implementasi manajemen pengetahuan sehingga dapat menjadi informasi penunjang dalam perumusan strategi pada PT Unilever Indonesia Tbk.

2. Memberikan informasi bagi pihak lain yang membutuhkan bahan rujukan untuk penelitian selanjutnya atau kegiatan lain yang berkaitan.

3. Sebagai bahan pembelajaran, meningkatkan pengetahuan dan penerapan ilmu-ilmu manajerial. 


\section{Metode Penelitian}

Menurut Sangkala (2007), faktor kunci lingkungan sosial yang mempengaruhi kesuksesan implementasi manajemen pengetahuan perusahaan yaitu perhatian, penilaian, pemberdayaan, kepercayaan, otonomi, pengungkitan kompetensi dan pekerja atau aktivis pengetahuan. Menurut Choi (2004) faktor kritis lingkungan sumber daya manusia (sosial) yang mempengaruhi kesuksesan implementasi manajemen pengetahuan adalah pelatihan karyawan, keterlibatan karyawan, kerja tim, pemberdayaan karyawan dan kepemimpinan manajemen puncak. Pendapat Sangkala (2007) memberikan istilah pelatihan dengan sebutan pengungkitan kompetensi karyawan, kepemimpinan manajemen puncak dengan sebutan pekerja /aktivis pengetahuan.

Berdasarkan acuan Sangkala (2007) dan Choi (2004), maka faktor-faktor lingkungan sosial yang akan diujikan dalam penelitian kali ini yaitu perhatian, penilaian, kepercayaan, otonomi, kerja tim, pengungkitan kompetensi, keterlibatan karyawan, pemberdayaan karyawan, dan kepemimpinan manajemen puncak. Faktor-faktor lingkungan sosial ini kemudian akan diuji pengaruhnya terhadap kesuksesan implementasi manajemen pengetahuan (kapabilitas organisasi untuk menciptakan, melakukan transfer, dan mengimplementasikan pengetahuan).

Uji t digunakan untuk menganalisis perbedaan antara tingkat kepentingan faktor lingkungan sosial yang diharapkan dengan kepentingan aktual yang diterapkan. Tingkat signifikan (alpha) yang digunakan pada penelitian ini adalah 0,05. Uji deskriptif digunakan untuk menganalisis nilai tertinggi dari tingkat harapan dan aktual serta nilai gap atribut pernyataan dari setiap faktor sosial. Analisis regresi berganda digunakan untuk menjelaskan hubungan dari 9 variabel independen (perhatian, penilaian, kepercayaan, otonomi, kerja tim, pengungkitan kompetensi, keterlibatan karyawan, pemberdayaan karyawan dan kepemimpinan manajemen puncak) terhadap kesuksesan implementasi manajemen pengetahuan (kapabilitas organisasi untuk menciptakan, melakukan transfer, dan mengimplementasikan pengetahuan). Kerangka pemikiran penelitian disajikan pada Gambar 1.

Penelitian dilakukan di kantor pusat PT Unilever Indonesia Tbk. yang beralamat di Jalan Jenderal Gatot Subroto, Kavling 15, Jakarta 12930. Kegiatan pengumpulan data dilakukan sejak April sampai dengan Juli 2010.

Data yang digunakan dalam penelitian ini adalah berupa data primer dan data sekunder. Data primer diperoleh melalui wawancara dan pengisian kuesioner langsung kepada karyawan dan pihak manajer yang terkait. Data sekunder diperoleh dari datadata seputar perusahaan, hasil studi pustaka seperti buku, jurnal, serta publikasi media yang berkaitan dan menunjang penelitian. Ukuran responden diperoleh dengan berdasarkan perhitungan secara matematis menggunakan rumus Slovin berikut:

Keterangan:

$$
n=\frac{N}{1+N e^{2}}
$$

$\mathrm{n}=$ Ukuran sampel

$\mathrm{N}=$ Ukuran populasi

e $\quad$ Kesalahan yang dapat ditolerir 
Jumlah karyawan di gedung PT. Unilever Indonesia Tbk adalah 600 orang. Tingkat kesalahan yang dapat ditolerir (e) ditentukan sebesar 0,1 atau 10 persen, maka jumlah sampel yang dibutuhkan minimal sebesar :

$$
n=\frac{600}{1+600(0,1)^{2}}
$$

$\mathrm{n}=85,7 \approx 86$ orang

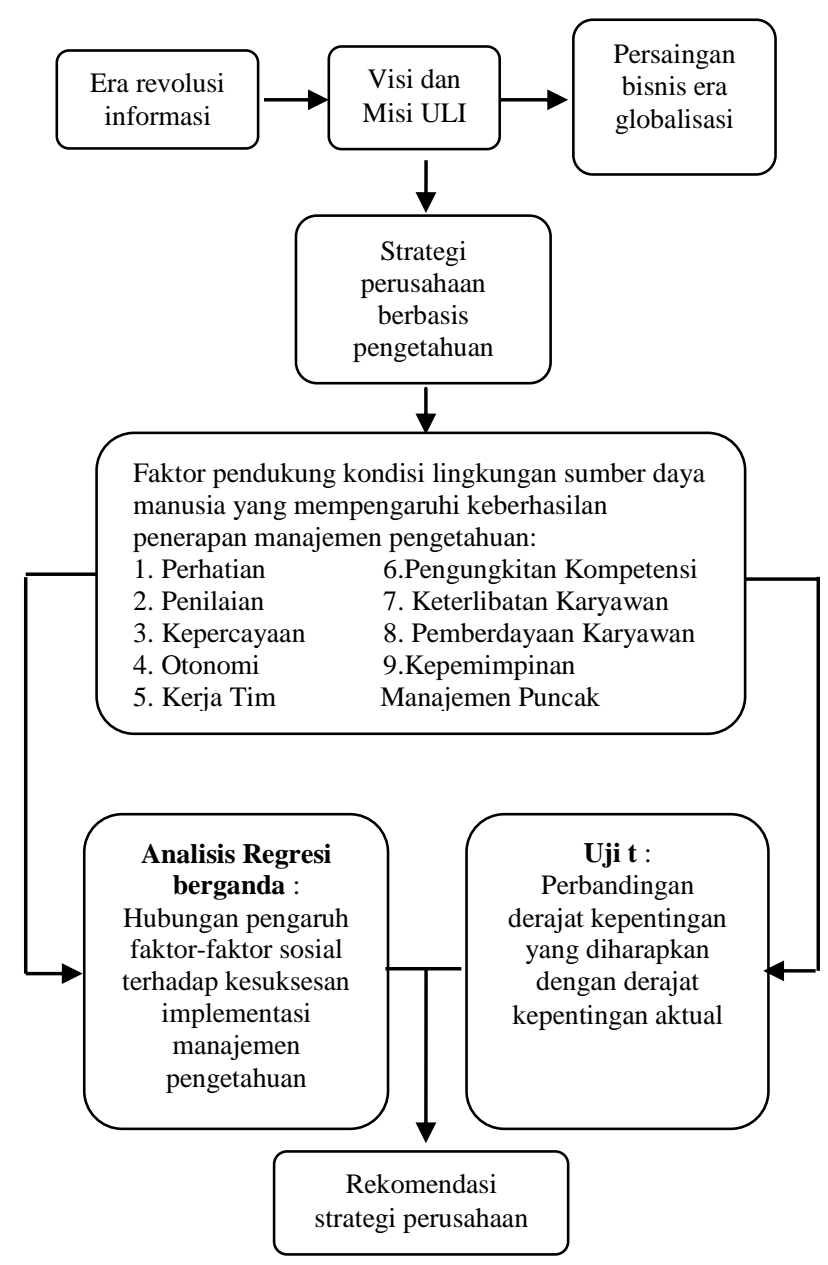

Gambar 1. Kerangka Pemikiran Penelitian

Validitas merupakan ukuran untuk menilai apakah alat ukur yang digunakan benarbenar mampu memberikan nilai peubah yang ingin diukur (Juanda, 2009). Pengujian validitas dilakukan dengan menggunakan teknik korelasi product moment. Instrumen penelitian adalah valid jika nilai $r$ hitung lebih besar $(>)$ dari nilai $r$ tabel. Nilai $r$ tabel yang digunakan pada taraf nyata 5 persen yaitu 0,21 sehingga butir pernyataan dinyatakan valid jika nilai $r$ hitung lebih besar dari 0,21 .

Menurut Juanda (2009), reliabilitas dapat didefinisikan sebagai ukuran untuk menilai apakah alat ukur yang digunakan mampu memberikan nilai pengukuran yang konsisten. Uji reliabilitas menyatakan bahwa instrumen penelitian adalah reliabel jika nilai hitung alfa lebih besar $(>)$ dari nilai $r$ tabel. Pengujian realibilitas dapat dilakukan dengan menggunakan teknik Alpha Cronbach. 
Analisis ini bersifat uraian dengan mengelompokkan, mengkategorikan, dan menganalisis data berupa jawaban kuesioner yang diperoleh dari tanggapan responden dengan menggunakan tabulasi data. Statistika deskriptif berusaha menjelaskan atau menggambarkan berbagai karakteristik data, seperti rata-rata, median, maupun variasi data.

Uji ini digunakan untuk mengetahui perbedaan nilai rata-rata populasi yang digunakan sebagai pembanding dengan rata-rata sebuah sampel. Pengujian menggunakan uji dua sisi dengan tingkat signifikansi $\alpha=5$ persen. Tingkat signifikansi dalam penelitian ini berarti mengambil risiko salah dalam mengambil keputusan untuk menolak hipotesis yang benar sebanyak-banyaknya 5 persen. Tabel distribusi t dicari pada $\alpha=2,5$ persen (uji dua sisi) dengan derajat kebebasan (df) 85 adalah sebesar 1,988. Kriteria Pengujian dalam uji $\mathrm{t}$ ini yaitu $\mathrm{HO}$ diterima dan $\mathrm{H} 1$ ditolak jika -t tabel $\mathrm{f} \mathrm{t}$ hitung $\mathrm{f} \mathrm{t}$ tabel. $\mathrm{HO}$ ditolak dan $\mathrm{H} 1$ diterima jika $-\mathrm{t}$ hitung $<-\mathrm{t}$ tabel atau $\mathrm{t}$ hitung $>\mathrm{t}$ tabel.

Berdasarkan Mattjik \& Sumertajaya (2000), persamaan regresi linier berganda adalah persamaan regresi dengan satu peubah tak bebas $(Y)$ dengan lebih dari satu peubah bebas $(X 1, X 2, \ldots . . X p)$. Beberapa asumsi yang mendasari model tersebut adalah residual menyebar saling bebas mengikuti sebaran normal, residual memiliki ragam homogen, tidak ada masalah kolinier, dan residual bebas terhadap peubah $\mathrm{X}$.

Keterandalan model dapat dilihat menggunakan koefisien determinasi $\left(R^{2}\right)$. Semakin besar nilai $\mathrm{R}^{2}$ berarti model semakin mampu menerangkan perilaku peubah $\mathrm{Y}$.

\section{Hasil Penelitian}

III.1. Implementasi Manajemen Pengetahuan pada PT Unilever Indonesia Tbk.

Unilever berusaha menerapkan learning culture. Proses belajar yang diterapkan dalam Unilever memiliki rumus atau filosofi 70-20-10, yaitu 70 persen belajar dengan metode on the job training, 20 persen coaching with line manager, dan 10 persen training. Filosofi tersebut juga merupakan salah satu strategi pengembangan sumber daya manusia yang didokumentasikan di dalam sistem Performance Development Plan (PDP) secara online. Performance Development Plan merupakan rencana pengembangan setiap karyawan yang disesuaikan dengan job description setiap posisi yang menjadi indikator keberhasilan kinerja karyawan selama tahun berjalan.

Konsep pembuatan PDP adalah "You Create Your Own Destiny", yaitu setiap karyawan diberikan kebebasan untuk membuat Key Performance Indicator (KPI) mereka masing-masing yang senantiasa disesuaikan dan harus sejalan dengan tujuan atau target perusahaan. Karyawan juga diberikan kewenangan untuk menentukan jenis pelatihan yang dirasa perlu untuk diikuti. Bentuk pelatihan yang diberikan ULI terbagi ke dalam tiga jenis pelatihan yaitu leadership training, general training, dan professional skill training.

Performance Development Plan yang telah dibuat oleh karyawan kemudian diusulkan dan didiskusikan ke atasan masing-masing untuk disetujui bersama. Pencapaian PDP ini dimonitor melalui Continuous Improvement Discussion (CID) yang dilakukan setiap pertengahan tahun. Di forum ini dibahas mengenai hal-hal apa saja yang perlu dilakukan untuk mengembangakan karyawan. 
Budaya pembelajar yang berusaha dibangun oleh ULI adalah budaya coaching dan budaya sharing knowledge. Budaya coaching diberi nama Building Leaders as Generative Coaches, yaitu para senior manajer ULI ditempatkan sebagai pembimbing untuk suatu departemen. Para senior manajer yang akan menjadi pembimbing akan dibekali pelatihan dan teknik coaching terlebih dahulu, sehingga mereka dapat menjadi coach yang baik dan membimbing dengan seksama.

Budaya pembelajar yang juga dibangun oleh ULI adalah budaya sharing knowledge. Setiap karyawan di semua lini diwajibkan untuk saling berbagi pengetahuan. Dalam proses berbagi pengetahuan ini dikenal adanya Learning Champion, yaitu orang yang dianggap ahli di bidangnya dan mereka secara sukarela berbagi pengetahuannya dengan rekan-rekan yang lain. Sistem budaya sharing knowledge yang dilakukan sangat bervariasi, misalnya dalam bentuk penghargaan ataupun di event-event tertentu, antara lain: Learning Award, Restropect, SOLAR (Share of learning and discussion) dan Good Idea.

Pengetahuan bersifat sangat dinamis dan dapat diperoleh dari mana saja. Oleh karena itu ULI membuka kemungkinan belajar dari seluruh stakeholdernya, seperti customer, supplier, mitra kerja, dan pihak-pihak lain yang terkait dengan bisnis ULI. Bentuk kegiatan yang dilakukan ULI untuk mendapatkan pengetahuan dari stakeholdernya misalnya dengan melakukan survey dan studi shopper understanding dengan pihak retail dan perusahaan marketing research. Hasil analisis survei tersebut dipakai sebagai acuan dalam pengembangan produk. Selain itu, ULI selalu mendengar kritik dan saran para konsumennya melalui suara konsumen Unilever. Kegiatankegiatan tersebut dapat memperkaya pengetahuan dan merupakan bentuk kepedulian dan perhatian ULI terhadap kebutuhan dan keinginan para stakeholdernya.

PT Unilever Indnesia menjadikan konsumen sebagai salah satu sumber pengetahuannya, ULI pun bertanggung jawab untuk memberikan pengetahuan kepada konsumen. Sebagai bentuk pertanggungjawaban ULI dalam mengedukasi konsumennya, beberapa program diselenggarakan dalam rangka berbagi pengetahuan untuk kehidupan masyarakat yang lebih baik di bidang kesehatan masyarakat, sanitasi lingkungan dan pengembangan ekonomi, seperti: program "Pepsodent sikat gigi pagi dan malam", kampanye Lifebouy Berbagi Sehat, Bekalmu untuk Bekali Sekolahku, program Stop Drugs Violation, HIV and AIDS among Teenagers, Unilever Green and Clean dan Shopping with Care.

Beberapa sarana dan fasilitas pendukung yang dibangun oleh ULI antara lain: Fasilitas belajar berupa Learning Centre di Mega Mendung, Puncak, Knowledge Club Online atau Online Library, Intranet, Kegiatan informal seperti SOJ (Sharing of Joy), Family Day dan POR (Pekan Olahraga) serta Kondisi ruangan kerja yang dibuat open space.

\section{2. Uji Validitas dan Reliabilitas}

Nilai $r$ hitung dari 29 pernyataan pada tingkat harapan dan tingkat aktual berkisar antara 0,35 sampai 0,69 maka semua pernyataan dinyatakan valid. Pengujian reliabilitas dilakukan dengan menggunakan teknik Alpha Cronbach. Nilai alfa cronbach berdasarkan perhitungan pada pernyataan tingkat harapan adalah 0,79 dan untuk pernyataan tingkat aktual adalah sebesar 0,93. Berdasarkan nilai tersebut, maka dapat 
dikatakan bahwa setiap butir pernyataan tingkat harapan dan tingkat aktual dalam kuesioner mampu memberikan nilai pengukuran yang konsisten.

\section{3. Karakteristik Responden}

Data yang diperoleh dari 86 responden menggambarkan bahwa dominasi pengisian kuesioner dilakukan oleh karyawan berjenis kelamin perempuan (66 persen), karyawan dengan usia 20-30 tahun (44 persen), karyawan dengan tingkat pendidikan terakhir sarjana (85 persen), dan karyawan dengan pengalaman masa kerja kurang dari 5 tahun (50\%). Karakteristik karyawan dapat dilihat lebih jelas padaTabel 1.

Tabel 1. Karakteristik Responden

\begin{tabular}{|c|c|c|c|}
\hline \multicolumn{2}{|r|}{ Karakteristik } & Jumlah & $(\%)$ \\
\hline \multirow[t]{4}{*}{1.} & Jenis Kelamin & & \\
\hline & Laki-laki & 29 & 34 \\
\hline & Perempuan & 57 & 66 \\
\hline & Total & 86 & 100 \\
\hline \multirow[t]{6}{*}{2.} & Usia & & \\
\hline & $20-30$ thn & 38 & 44 \\
\hline & $31-40$ thn $41-50$ thn & 30 & 35 \\
\hline & $>50$ thn & 12 & 14 \\
\hline & & 6 & 7 \\
\hline & Total & 86 & 100 \\
\hline \multirow[t]{6}{*}{3.} & Pendidikan Terakhir & & \\
\hline & SMA & 3 & 3 \\
\hline & Diploma & 4 & 5 \\
\hline & Sarjana & 73 & 85 \\
\hline & Pasca sarjana & 6 & 7 \\
\hline & Total & 86 & 100 \\
\hline \multirow[t]{8}{*}{4.} & Masa Kerja & & \\
\hline & $<5$ thn & 43 & 50 \\
\hline & $6-10$ thn & 22 & 26 \\
\hline & $11-15$ thn & 8 & 9 \\
\hline & $16-20$ thn & 5 & 6 \\
\hline & $21-25$ thn & 2 & 2 \\
\hline & $>25$ thn & 6 & 7 \\
\hline & Total & 86 & 100 \\
\hline
\end{tabular}

\section{4. Pengujian Satu Sampel}

Hipotesis yang akan diuji pada uji perbedaan rata-rata ini adalah:

HO : Derajat kepentingan yang diharapkan karyawan tidak berbeda dengan derajat kepentingan aktual yang diterapkan oleh perusahaan.

H1: Derajat kepentingan yang diharapkan karyawan berbeda dengan derajat kepentingan aktual yang diterapkan oleh Perusahaan.

Berdasarkan hasil pengolahan data didapatkan nilai t hitung sebesar 1,87 dan $P$ value sebesar 0,06 . Nilai $t$ tabel dengan pengujian dua sisi (signifikansi $=0,03$ ) adalah sebesar 1,99 . Nilai t hitung lebih kecil dari $(<) \mathrm{t}$ tabel dan nilai $\mathrm{P}$ value lebih besar dari (>) 0,05, maka $\mathrm{HO}$ diterima dan $\mathrm{H} 1$ ditolak artinya bahwa derajat kepentingan yang diharapkan karyawan tidak berbeda dengan derajat kepentingan aktual yang diterapkan di perusahaan. 
Hasil pengujian satu sampel menunjukkan tidak adanya perbedaan antara harapan karyawan dengan penerapan oleh perusahaan. Kondisi ini menunjukkan suasana yang kondusif di lingkungan sosial ULI dalam mengimplementasikan manajemen pengetahuan. Berbagai bentuk kegiatan, sarana dan prasarana yang selama ini diterapkan dalam implementasi manajemen pengetahuan dinilai sesuai dengan keinginan karyawan sehingga proses penciptaan, pentransferan dan pemanfaatan pengetahuan dapat berjalan dengan baik. Proses manajemen pengetahuan yang baik kemudian akan mengantarkan perusahaan pada kepemilikan sumber daya pengetahuan yang berdaya saing.

\section{5. Analisis Kesenjangan Faktor-Faktor Sosial}

Perbedaan antara nilai kepentingan yang diharapkan dengan yang aktual dari setiap faktor sosial dijabarkan menjadi atribut-atribut pernyataan. Derajat kepentingan tertinggi yang diharapkan oleh karyawan adalah pada faktor Pemberdayaan Karyawan (h3) dengan nilai rata-rata sebesar 4,91 yaitu "dukungan Perusahaan terhadap pencarian keahlian/keunggulan yang dimiliki oleh karyawan". Derajat kepentingan tertinggi yang diterapkan di Perusahaan adalah pada faktor Pengungkitan Kompetensi (f2) dengan nilai rata-rata sebesar 4,49 yaitu "menyediakan informasi yang lengkap mengenai dasar-dasar manajemen pengetahuan melalui training". Nilai rata-rata (mean) harapan dan aktual serta nilai kesenjangan (gap) dari setiap atribut faktor sosial disajikan pada Tabel 2.

Tabel 2. Nilai Mean Harapan, Aktual dan Nilai Kesenjangan (Gap)

\begin{tabular}{|c|c|c|c|}
\hline Predictors & Mean Harapan & Mean Aktual & Gap \\
\hline a1 & 4,3721 & 4,3023 & 0,07 \\
\hline a2 & 3,8837 & 4,0349 & $-0,151$ \\
\hline a3 & 4,3605 & 4,3372 & 0,023 \\
\hline b1 & 4,2674 & 4,0581 & 0,2093 \\
\hline b2 & 4,2326 & 4,1744 & 0,0582 \\
\hline b3 & 4,3023 & 4,0581 & 0,2442 \\
\hline c1 & 4,3837 & 4,2209 & 0,1628 \\
\hline c2 & 4,1047 & 4,1047 & 0 \\
\hline c3 & 4,2791 & 4,2791 & 0 \\
\hline d1 & 4,1744 & 4,0581 & 0.1163 \\
\hline d2 & 4,4535 & 4,2907 & 0.1628 \\
\hline d3 & 4,4884 & 4,3837 & 0.1047 \\
\hline e1 & 4,6395 & 4,4419 & 0,1976 \\
\hline e2 & 4,4070 & 4,2907 & 0,1163 \\
\hline e3 & 4,4535 & 4,2907 & 0,1628 \\
\hline $\mathrm{f} 1$ & 4,4651 & 4,3721 & 0,093 \\
\hline $\mathrm{f} 2$ & 4,4186 & 4,4884 & $-0,0698$ \\
\hline f3 & 4,4070 & 4,3256 & 0,0814 \\
\hline g1 & 4,1860 & 4,1279 & 0,0581 \\
\hline g2 & 4,3488 & 4,2791 & 0,0697 \\
\hline g3 & 4,3256 & 4,2209 & 0,1047 \\
\hline g4 & 4,3256 & 4,2791 & 0,0465 \\
\hline h1 & 4,2093 & 4,3140 & $-0,1047$ \\
\hline h2 & 4,3605 & 4,4186 & $-0,0581$ \\
\hline h3 & 4,9070 & 4,3023 & 0,6047 \\
\hline i1 & 4,3605 & 4,2209 & 0.1396 \\
\hline ¡2 & 4,2558 & 4,1628 & 0.093 \\
\hline ¡3 & 4,2558 & 4,2326 & 0.0232 \\
\hline i4 & 4,2674 & 4,2791 & -0.0117 \\
\hline
\end{tabular}




\section{6. Analisis Regresi Linier Berganda}

Pada penelitian ini, variabel independen terdiri dari sembilan faktor lingkungan sosial yaitu perhatian, penilaian, kepercayaan, otonomi karyawan, kerja tim, pengungkitan kompetensi, keterlibatan, pemberdayaan, dan kepemimpinan manajemen puncak. Variabel dependen pada penelitian ini adalah kesuksesan implementasi manajemen pengetahuan (kapabilitas organisasi untuk menciptakan, melakukan transfer, dan mengimplementasikan pengetahuan). Arah hubungan variabel independen berkorelasi positif atau negatif terhadap variabel independen dapat dilihat melalui koefisien dari persamaan regresi. Nilai dan sifat koefisien variabel independen disajikan pada Tabel 3.

Tabel 3. Hasil Analisis Regresi Linier Berganda

\begin{tabular}{lrr}
\hline \multicolumn{1}{c}{ Predictor } & B Coef & SE Coef \\
\hline Constant & 22.835 & 5.893 \\
Perhatian (x1) & -0.145 & 1.181 \\
Penilaian (x2) & -1.357 & 0.9328 \\
Kepercayaan (x3) & -2.091 & 1.014 \\
Otonomi karyawan (x4) & 2.396 & 1.238 \\
Kerja Tim (x5) & 0.420 & 1.480 \\
Pengungkitan Kompetensi (x6) & 2.028 & 1.174 \\
Keterlibatan Karyawan (x7) & 3.129 & 1.155 \\
Pemberdayaan Karyawan (x8) & 4.073 & 1.329 \\
Kepemimpinan Manajemen Puncak (x9) & 1.675 & 1.425 \\
\multicolumn{2}{c}{ S=4,23791 R-Sq = 53,9\% R-Sq(adj) $=48,4 \%$ F = 9,87 } \\
\hline
\end{tabular}

Berdasarkan Tabel 3, dapat dibuat persamaan regresi sebagai berikut:

$Y=22,835-0,145 X 1-1,357 X 2-2,091 X 3+2,396 X 4+0,420 X 5+2,028 X 5+3,129 X 7+$

$$
4,073 \times 8+1,675 \times 9
$$

Nilai Adjusted $R$ square pada model regresi ini adalah 0,48 . Hal ini mengindikasikan persentase sumbangan pengaruh faktor lingkungan sosial terhadap variabel kesuksesan implementasi manajemen pengetahuan adalah sebesar 48,4 persen sedangkan sisanya sebesar 51,6 persen dipengaruhi atau dijelaskan oleh variabel lain yang tidak dimasukkan dalam model penelitian ini diantaranya yaitu faktor kondisi organisasi dan kondisi teknologi.

Uji Koefisien Regresi Secara Bersama-sama (Uji F) perlu digunakan untuk mengetahui apakah faktor-faktor lingkungan sosial secara bersama-sama berpengaruh secara signifikan terhadap kesuksesan implementasi manajemen pengetahuan ( $\mathrm{Y}$ ). Hipotesis yang akan diuji adalah:

HO : Tidak ada pengaruh secara signifikan antara faktor-faktor lingkungan sosial secara bersama-sama terhadap kesuksesan implementasi manajemen pengetahuan.

H1 : Ada pengaruh secara signifikan antara faktor-faktor lingkungan sosial secara bersama-sama terhadap kesuksesan implementasi manajemen pengetahuan.

Kriteria pengujian hipotesis adalah Ho diterima bila $\mathrm{F}$ hitung $\mathrm{F}$ tabel dan Ho ditolak bila F hitung lebih besar dari (>) F tabel. Nilai F hitung adalah sebesar 9,87. Signifikansi yang digunakan adalah $\alpha=5 \%$, df 1 (jumlah variabel-1) = 9, dan df2 (n-k-1) atau 86-9-1 $=76$. Hasil diperoleh untuk $F$ tabel adalah sebesar 2. Pada uji $F$ ini, $F$ hitung lebih besar dari $F$ tabel $(9,88>2)$ maka Ho ditolak, artinya faktor-faktor lingkungan sosial secara 
bersama-sama memiliki pengaruh secara signifikan terhadap kesuksesan implementasi manajemen pengetahuan di PT Unilever Indonesia Tbk.

Uji koefisien regresi secara parsial perlu digunakan untuk mengetahui apakah dalam model regresi variabel independen $(X 1, X 2, X 3, \ldots . . . X 9)$ secara parsial berpengaruh signifikan terhadap variabel dependen $(\mathrm{Y})$. Hipotesis yang akan diuji adalah:

HO: Secara parsial tidak ada pengaruh signifikan antara faktor independen dengan faktor dependen

H1: Secara parsial ada pengaruh signifikan antara faktor independen dengan faktor dependen.

Kriteria pengujian hipotesis yaitu $\mathrm{HO}$ diterima jika $-\mathrm{t}$ tabel $€ \mathrm{t}$ hitung $€ \mathrm{t}$ tabel, $\mathrm{HO}$ ditolak jika - t hitung < - $\mathrm{t}$ tabel atau $\mathrm{t}$ hitung $>\mathrm{t}$ tabel. Nilai $\mathrm{t}$ tabel dicari pada $\alpha=5 \%$ : $2=2,5 \%$ (uji dua sisi) dengan derajat kebebasan (df) $n-k-1$ atau 86-9-1 $=76$. Hasil pencarian $t$ tabel yaitu sebesar 1,99. Nilai t hitung dapat dilihat pada Tabel 4.

Tabel 4. Hasil Uji t

\begin{tabular}{|c|c|c|c|}
\hline Predictor & B Coef. & $T$ & $\mathrm{P}$ \\
\hline Constant & 22,835 & 3,87 & 0,000 \\
\hline Perhatian (x1) & $-0,145$ & $-0,12$ & 0,903 \\
\hline Penilaian (x2) & $-1,357$ & $-1,45$ & 0,150 \\
\hline Kepercayaan (x3) & -2.091 & $-2,06$ & 0,043 \\
\hline Otonomi karyawan $(x 4)$ & 2,396 & 1,94 & 0,057 \\
\hline Kerja Tim (x5) & 0,420 & 0,28 & 0,778 \\
\hline Pengungkitan Kompetensi (x6) & 2,028 & 1,73 & 0,088 \\
\hline Keterlibatan Karyawan (x7) & 3,129 & 2,71 & 0,008 \\
\hline Pemberdayaan Karyawan (x8) & 4.073 & 3,06 & 0,003 \\
\hline Kepemimpinan Manajemen Puncak (x9) & 1.675 & 1,18 & 0,243 \\
\hline
\end{tabular}

Berdasarkan hasil uji $t$, terdapat empat variabel independen yang berpengaruh secara nyata terhadap kesuksesan implementasi manajemen pengetahuan pada ULI, yaitu Kepercayaan, Otonomi karyawan, Keterlibatan Karyawan, dan Pemberdayaan karyawan. Variabel-variabel independen tersebut memiliki nilai T lebih besar dari 1,99 dan nilai P lebih kecil dari 0,05.

Faktor Kepercayaan memiliki pengaruh yang paling rendah dan bersifat negatif terhadap kesuksesan implementasi manajemen pengetahuan pada ULI. Hal ini dapat dilihat dari nilai koefisiennya yang bertanda negatif. Semakin besar tingkat kepercayaan justru menurunkan tingkat kesuksesan implementasi manajemen pengetahuan. Tingginya kepercayaan antarindividu dapat menjadikan individu itu kurang memiliki keinginan untuk mencari tahu lebih dalam ataupun mencari tahu tentang kebenaran dari pengetahuan yang didapatkannya. Kondisi ini merupakan hambatan dalam menciptakan pengetahuan baru, sehingga disebut sebagai faktor yang memiliki korelasi negatif terhadap kesuksesan implementasi manajemen pengetahuan.

Faktor Otonomi Karyawan memiliki pengaruh nyata yang bersifat positif terhadap kesuksesan implementasi manajemen pengetahuan. Semakin besar tingkat otonomi karyawan yang diberikan oleh Perusahaan maka karyawan merasa diberikan keleluasaan dalam menciptakan, melakukan transfer dan mengimplementasikan 
pengetahuan sehingga hal ini akan meningkatkan kesuksesan implementasi manajemen pengetahuan.

Faktor Keterlibatan Karyawan memiliki pengaruh nyata yang bersifat positif terhadap kesuksesan implementasi manajemen pengetahuan pada ULI. Semakin tinggi tingkat keterlibatan karyawan maka semakin besar kontribusi karyawan dalam mencapai tujuan organisasi. Semakin banyak keterlibatan karyawan dalam setiap kegiatan penciptaan, berbagi dan pemanfaatan pengetahuan maka semakin banyak pengetahuan yang dapat diperoleh dan dimanfaatkan oleh Perusahaan sehingga dapat meningkatkan kesuksesan implementasi manajemen pengetahuan.

Faktor Pemberdayaan Karyawan merupakan faktor yang paling berpengaruh nyata terhadap kesuksesan implementasi manajemen pengetahuan pada ULI. Pengaruh faktor Pemberdayaan Karyawan berpengaruh positif terhadap kesuksesan implementasi manajemen pengetahuan pada ULI. Semakin tinggi tingkat pemberdayaan karyawan maka semakin baik keahlian yang dimiliki oleh karyawan yang kemudian dapat dijadikan sebagai sumber penciptaan pengetahuan.

Faktor Perhatian, Penilaian, Kerja Tim, dan Kepemimpinan Manajemen Puncak tidak memiliki pengaruh nyata terhadap kesuksesan implementasi manajemen pengetahuan pada ULI. Hal ini dikarenakan nilai T setiap faktor yang lebih kecil dari 1,99 dan nilai $P$ yang lebih besar dari 0,05.

\section{7. Uji Best Subsets Regression}

Best Subsets Regression merupakan salah satu cara yang digunakan untuk mengetahui variasi bentuk model lain yang dapat dibuat dengan variabel dependen dan independen yang sama. Hasil dari uji ini dapat menunjukkan bentuk model regresi terbaik. Salah satu cara yang digunakan untuk memilih model regresi terbaik adalah dengan cara melihat nilai dari R-square (adj) terbesar. Pada penelitian ini dipilih model regresi dengan nilai $R$-square (adj) sebesar 49,7 persen.

Model regresi terbaik diperoleh dengan memasukkan tujuh variabel ke dalam model, yaitu Penilaian (x2), Kepercayaan (x3), Otonomi (x4), Pengungkitan Kompetensi (x6), Keterlibatan Karyawan (x7), Pemberdayaan Karyawan (x8) dan Kepemimpinan Manajemen Puncak (x9). Variabel perhatian (x1) dan kerja tim (x5) tidak dimasukkan ke dalam model regresi karena tidak memiliki hubungan yang nyata terhadap kesuksesan implementasi manajemen pengetahuan, hal ini dapat diketahui dari $\mathrm{P}$ value $X 1$ dan X2 secara berturut-turut yaitu 0,90 dan 0,78 . Nilai tersebut berada jauh lebih besar dari taraf nyata yang digunakan yaitu 0,05 .

Tabel 5 menyajikan hasil analisis regresi linier berganda berdasarkan pemilihan uji Best Subsets Regression. Persamaan regresi baru yaitu:

$$
Y=23,2-1,35 \times 2-2,10 \times 3+2,44 X 4+2,09 \times 6+3,14 \times 7+4,13 \times 8+1,73
$$

$$
\mathrm{X} 9 .
$$

Persamaan regresi yang baru ini tidak mengubah sifat pengaruh variabel independen terhadap variabel dependen, namun hanya mengubah nilai koefisiennya.

Model regresi ini memiliki nilai R-square (adj) sebesar 0,497 yang memiliki arti bahwa 49,7 persen kesuksesan implementasi manajemen pengetahuan di ULI dapat dijelaskan oleh tujuh variabel independen yaitu faktor penilaian, kepercayaan, otonomi, pengungkitan kompetensi, keterlibatan karyawan, pemberdayaan karyawan, 
dan kepemimpinan manajemen puncak. Nilai $F$ hitung lebih besar dari $F$ table $(13>2,06)$ artinya faktor-faktor lingkungan sosial secara bersama-sama memiliki pengaruh secara signifikan antara terhadap kesuksesan implementasi manajemen pengetahuan di PT Unilever Indonesia Tbk.

Nilai T pada tabel mengindikasikan pengaruh secara parsial dari tiap-tiap variabel terhadap kesuksesan implementasi manajemen pengetahuan. Variabel yang secara parsial memiliki pengaruh nyata terhadap kesuksesan implementasi manajemen pengetahuan adalah kepercayaan, otonomi karyawan, keterlibatan karyawan dan pemberdayaan karyawan. Faktor-faktor yang tidak memiliki pengaruh nyata terhadap kesuksesan implementasi manajemen pengetahuan adalah faktor perhatian, penilaian, kerja tim, pengungkitan kompetensi, dan kepemimpinan manajemen puncak.

Tabel 5. Hasil Analisis Regresi Linier Berganda dengan Tujuh Variabel

\begin{tabular}{lrrrr}
\multicolumn{1}{c}{ Predictor } & B Coef. & SE Coef & \multicolumn{1}{c}{ T } & P \\
\hline Constant & 23,153 & 5,369 & 4,31 & 0,000 \\
Penilaian (x2) & $-1,3536$ & 0.9200 & $-1,47$ & 0,145 \\
Kepercayaan (x3) & -2.0989 & 0,9888 & $-2,12$ & 0,037 \\
Otonomi (x4) & 2,444 & 1.201 & 2,04 & 0,045 \\
Pengungkitan Kompetensi & 2,086 & 1.132 & 1,84 & 0,069 \\
(x6) & & & & \\
Keterlibatan (x7) & 3,139 & 1.136 & 2,76 & 0,007 \\
Pemberdayaan (x8) & 4.126 & 1.254 & 3,29 & 0,002 \\
Kepemimpinan (x9) & 1.731 & 1.361 & 1,27 & 0,207 \\
& $\mathrm{~S}=4.18573$ & R-Sq = 53.8\% & R-Sq(adj) = 49,7\% F = 13 & \\
\hline
\end{tabular}

\section{Kesimpulan}

PT Unilever Indonesia (ULI) mengimplementasikan manajemen pengetahuan dalam lima bentuk pendekatan yaitu berupa pengembangan sumber daya manusia, budaya pembelajar, menjadikan pengetahuan stakeholder sebagai salah satu sumber pengetahuan, edukasi masyarakat dan penyediaan fasilitas-fasilitas pendukung. Salah satu metode pengembangan sumber daya manusia yang dilakukan oleh ULI menggunakan filosofi 70-20-10, yaitu 70 persen belajar dengan metode on the job training, 20 persen coaching with line manager, dan 10 persen training. Filosofi ini didokumentasikan di dalam sistem Performance Development Plan (PDP) secara online.

Budaya pembelajar di ULI dikembangakan melalui budaya coaching dan budaya sharing knowledge. Budaya coaching diberi nama Building Leaders as Generative Coaches, yaitu para senior manajer ULI ditempatkan sebagai pembimbing untuk suatu departemen. Budaya sharing knowledge dikembangkan melalui kegiatan-kegiatan menarik seperti Learning Award, Restropect, Share of learning and discussion (SOLAR), dan Good Idea. Perusahaan membuka kemungkinan belajar dari seluruh stakeholdernya. Salah satu cara yang dilakukan yaitu dengan melakukan survei dan studi shopper understanding dengan pihak retail dan perusahaan marketing research. Selain itu, ULI juga selalu mendengar kritik dan saran para konsumennya melalui suara konsumen Unilever.

Edukasi kepada masyarakat dilakukan ULI melalui beberapa kegiatan seperti program "Pepsodent sikat gigi pagi dan malam", kampanye Lifebouy Berbagi Sehat, Bekalmu untuk Bekali Sekolahku, program Stop Drugs Violation, HIV and AIDS among 
Teenagers, Unilever Green and Clean dan Shopping with Care. Perusahaan juga menyediakan sarana dan fasilitas pendukung terciptanya manajemen pengetahuan yang efektif, diantaranya yaitu Learning Centre, Knowledge Club Online, Intranet, Kegiatan informal (Sharing of Joy, Family Day, dan Pekan Olahraga), serta Kondisi ruangan kerja yang dibuat open space.

Derajat kepentingan yang diharapkan karyawan tidak berbeda nyata dengan derajat kepentingan aktual yang diimplementasikan oleh Perusahaan. Derajat kepentingan tertinggi yang diharapkan oleh karyawan adalah pada faktor Pemberdayaan karyawan dengan nilai rata-rata sebesar 4,9070 yaitu "Dukungan Perusahaan terhadap pencarian keahlian/keunggulan yang dimiliki oleh karyawan". Derajat kepentingan tertinggi yang diterapkan di Perusahaan adalah pada faktor pengungkitan kompetensi dengan nilai rata-rata sebesar 4,4884 yaitu "Menyediakan informasi yang lengkap mengenai dasardasar manajemen pengetahuan melalui training".

Faktor-faktor kunci kesuksesan implementasi manajemen pengetahuan yaitu kepercayaan, otonomi, keterlibatan dan pemberdayaan karyawan. Semakin rendah tingkat kepercayaan dan semakin tinggi tingkat otonomi, keterlibatan serta pemberdayaan karyawan maka semakin tinggi tingkat kesuksesan implementasi manajemen pengetahuan pada PT Unilever Indonesia.

\section{Daftar Pustaka}

Choi YS. 2004. Knowledge Management Supportive Human Resource Environment. Journal of the Academy of Business and Economics.

Davenport, T.H., \& L. Prusak. Working Knowledge: How Organizations Manage What They Know. 1998. Harvard Business School Press. Boston.

Davidson, C. \& P.Voss. 2003. Knowledge Management, An Introduction to creating competitive advantage from intellectual capital. Vision Book. New Delhi.

Fatwan S \& A.Denni. 2009. Indonesian MAKE Study and \& Lessons Learned from the Winners. PT Gramedia Pustaka Utama. Jakarta.

Human Capital Magazine. September 2007. Mengembangkan Strategi Berbasis Knowledge, Human Capital Magazine, edisi 42.

Juanda B. 2009. Metodologi Penelitian Ekonomi dan Bisnis. IPB Press. Bogor.

Mattjik AS \& M. Sumertajaya. 2000. Perancangan Percobaan Dengan Aplikasi SAS dan Minitab Jilid 1. IPB Press. Bogor.

Nonaka I \& H. Takeuchi. 1995. The Knowledge-Creating Company. Oxford University Press. New York.

Nonaka I \& N. Konno. 1998. The Concept of "BA": Building A Fondation for Knowledge Creation. California Management Review. 40(3): 40-55.

Nonaka I \& R. Toyama. 2002. A Firm as A Dialectical Being: Towards A Dynamic Theory of A Firm. Industrial and Corporate Change. 11(5):995-1009. 
. 2005. The Theory of The Knowledge-Creating Firm: Subjectivity, Objectivity and Synthesis . Industrial and Corporate Change. 14(3):419-436. . 2007. Strategic Management as Distributed Practical wisdom (Phronesis). Industrial and Corporate Change. 16(3):371-394.

Quinn, J., B., P.Anderson \& S. Finkelstein. 1998. Managing Professional Intellect: Making the Most of the Best. In Harvard Business Review on Knowledge Management. Harvard Business School Publishing. Boston.

Rupidara, NS. 2008. Modal Intelektual dan Strategi Pengembangan Organisasi dan Sumber Daya Manusia. In: Prosiding Forum Diskusi Pusat Studi Kawasan Timur Indonesia 21 Februari 2008. Universitas Kristen Satya Wacana.

Sangkala. 2007. Knowledge Management. PT Raja Grafindo Persada. Jakarta.

Setiarso B, N. Harjanto, Triyono \& S.Hendro. 2009. Penerapan Knowledge Management pada Organisasi. Graha Ilmu. Yogyakarta.

Teece DJ. 2000. Managing Intellectual Capital. Oxford University. Press. New York.

Yuliazmi. 2005. Penerapan Knowledege Management Pada Perusahaan Reasuransi : Studi Kasus PT Reasuransi Nasional Indonesia. Thesis. Fakultas Pasca Sarjana Universitas Budi Luhur. Jakarta. 